\title{
Housing and health promotion: moving forward
}

\author{
Roderick J. Lawrence
}

Published online: 9 February 2010

(C) Swiss School of Public Health 2010

During the last three decades, many empirical studies have analysed the relationships between housing conditions and the health status of residents. Numerous international conferences have been held to debate key issues. Scientific and professional journals have published special issues (Hartig and Lawrence 2003). The European Office of the World Health Organization in Bonn founded a Taskforce on Housing and Health in 2001. A major pan-European household survey of housing and health coordinated by the World Health Organization was completed in eight European cities in 2003 (WHO Regional Office for Europe 2007). Housing and Health were a topic included in the agenda of the fourth Ministerial Conference on Environment and Health held in Budapest in June 2004. Given the breadth and scope of contributions on housing and health during recent years, it is appropriate to analyse whether the links to health promotion have been explicit during this period.

In the field of health promotion, health is not considered as an abstract condition, but as the ability of an individual to achieve her/his potential and to respond positively to the challenges of daily life. Therefore, health is an asset or a resource for everyday life, rather than a standard or goal that ought to be achieved. This interpretation is pertinent for the field of housing and health because empirical evidence shows that the environmental and social conditions inside specific housing units and residential neighbourhoods do impact on human relations, may induce stress, and can have positive or negative impacts on quality of life

\section{R. J. Lawrence $(\square)$}

Human Ecology, Institute of Environmental Sciences,

Faculty of Social and Economic Sciences, University of Geneva,

Route de Drize 7, 1227 Carouge (GE), Switzerland

e-mail: Roderick.Lawrence@unige.ch and well being of households and individuals (Halpern 1995; Shaw 2004). Given the multiple factors that influence health, it should be evident that interdisciplinary approaches are necessary to study the health of people in all kinds of residential neighbourhoods.

Housing is a physical fabric that is meant to address basic human needs for shelter and security by providing protection against climatic conditions (excessive heat and cold) and unwanted intrusions from insects, rodents and environmental nuisances, such as noise that may be harmful for health and well being (Lawrence 2004). Housing contains household activities and possessions. Housing can also be interpreted as a process by referring to the provision and maintenance of all kinds of residential buildings either by public authorities or private initiatives. The United Nations stresses that housing is a basic human right including the right to habitable and affordable shelter, legal security of tenure, and the availability of community services and infrastructure.

The housing environment can also be considered in terms of its capacity to nurture and sustain social and psychological processes (Halpern 1995). For example, the capacity of the resident in her/his home environment to alleviate stress accumulated at school or in the workplace, and whether this capacity is mediated by views of nature or being in natural surroundings, such as urban parks (Abraham et al. 2009). In addition, the physical condition of housing units should be examined with respect to forms of housing tenure, household composition and income, the availability and cost of building materials, infrastructure and services, the levels of education, and the employment status of residents. These dimensions of housing environments and the health of residents should not be isolated from their diet, lifestyle, employment status and the availability of health care. Hartig and Lawrence 
(2003) have used the term "the residential context of health" to refer to all these dimensions.

Housing and health has been a topic on the agenda of public health since the mid-nineteenth century.

At that time, the shared concern of doctors, engineers, housing reformers and politicians was how to reduce the high risk of mortality and morbidity stemming from infectious diseases in urban neighbourhoods, especially those in which unsanitary housing conditions were present. This concern was largely based on evidence, including statistical evidence, which showed that those who lived in substandard housing were at higher risk. Today, the evidence is similar, not just in cities of so-called 'developing countries', but also developed countries (Fuller-Thomson et al. 2000).

When housing and the built environment are considered too narrowly then the interrelations between housing, health and well being may not seem important. For example, if housing units are built such that their physical fabric only meets minimum building standards, then the sociopsychological dimensions of the home environment will probably be overlooked to the detriment of the mental health of the residents. There is a growing recognition of a need for innovative approaches in the field of housing and health. The common interpretation of academics, professionals and policy makers, who only address the treatment of symptoms rather than the fundamental issues at stake, can be replaced by a broader more holistic approach. Lawrence (2004) argues that interdisciplinary approaches can highlight the difference between a discipline-based interpretation of housing and health and one that rejects a symptom-treatment explanation based on a biomedical model by combining the interpretation of biological, cultural, economic, political, psychological and social factors in a new way.

The 20th IUHPE World Conference on Health Promotion to be held in Geneva, Switzerland, from 11 to 15 July 2010 will provide a multidisciplinary platform for presentations and debate on this much neglected field which is still too frequently taken for granted. Visit the conference programme at: http://www.iuhpeconference.net.

\section{References}

Abraham A, Sommerhalder K, Abel T (2009) Landscape and wellbeing: a scoping study on the health-promoting impact of outdoor environments. Int J Public Health. doi:10.1007/s00038009-0069-z

Fuller-Thomson E, Hulchanski D, Wang S (2000) The health-housing relationship: what do we know? Rev Environ Health 15:109-134

Halpern D (1995) Mental health and the built environment: more than bricks and mortar? Taylor \& Francis, London

Hartig T, Lawrence R (eds) (2003) The residential context of health. $\mathrm{J}$ Soc Issues 59:455-650

Lawrence R (2004) Housing and health: from interdisciplinary principles to transdisciplinary research and practice. Futures 36:487-502

Shaw M (2004) Housing and public health. Annu Rev Public Health 25:397-418

WHO Regional Office for Europe (2007) Large analysis and review of European housing and health status (LARES). WHO Regional Office for Europe, Bonn. http://www.euro.who.int/Housing/ lares/20080403_1 